\title{
A MUNICIPALIZAÇÃO DAS AÇÕES DE SAÚDE E A ASSISTÊNCIA HOSPITALAR: AS RESPOSTAS DE SANTO ANDRÉ E DIADEMA (1989-1992)*
}

Vânia Barbosa do Nascimento**

Resumo: A oferta de serviços hospitalares diante do recente processo políticoadministrativo de descentralização e municipalização da saúde no Brasil surge como um desafio à gestão local. Produzir respostas imediatas, num contexto dinâmico, acelerado e não linear de incorporação politica dos direitos sociais, associado à complexidade que envolve a assistência médico-hospitalar, conduz a uma necessária reflexão acerca das potencialidades e limites das diretrizes da atual política de saúde. As diferentes trajetórias do desenvolvimento dos projetos para a gestão de serviços hospitalares nos municípios de Santo André e Diadema inovam, diante dos aspectos conceituais e políticos da descentralização, as responsabilidade do poder local, apesar da complexidade da questão.

Palavras-chave: assistência médico-hospitalar; gestão local de serviços hospitalares;municipalização; descentralização

* NASCIMENTO, V.B.. Descentralização, Municipalização e Assistência Hospitalar: As Experiências dos Municipios de Santo André e Diadema. Dissertação de Mestrado apresentada ao Departamento de Medicina Preventiva da Faculdade de Medicina da USP, São Paulo, 1994.

** Médica Sanitarista, Mestre em Medicina Preventiva - Docente do Departamento de Medicina Preventiva da Faculdade de Medicina do ABC. 


\section{INTRODUÇÃO}

A nova orientação política de direito social e obrigação do Estado para com as ações e serviços de saúde, expressa em determinação legal, a partir das diretrizes constitucionais de descentralização, atendimento integral e participação da comunidade, não esgota a necessidade de uma contínua reflexão(BRASIL (1988). Até porque tem sido demonstrado, no decorrer de sua instituição, dificuldades e contradições que obrigam a recuperação histórica dos processos políticos, econômicos, sociais e culturais que determinaram a formação da complexa estrutura organizacional na saúde que se pretende alterar.

Neste sentido, a estruturação de um sistema local de saúde, com base na equidade dos direitos sociais, coloca como desafio rever os modelos de atenção médica construídos no passado sob a intervenção do Estado. Em última instância, significa reverter um perfil organizado de atenção à saúde marcado por dicotomias entre ações coletivas e assistência individual, atenção básica e universal versus atenção resolutiva e restritiva.

Ao ser pensada a estratégia de descentralização no Brasil, enquanto projeto de intervenção, que se insere de um modo geral no processo de democratização do Estado - a conseqüente distribuição mais eqüitativa de bens e serviços à população com participação social e transferência real de poder de decisão às unidades territoriais -, a assistência hospitalar constitui-se numa grande tarefa, na medida em que procura-se viabilizar um programa técnico e político de direitos sociais.

Contudo, ao situar o hospital no contexto histórico de sua aparição identificam-se contradições de ordem técnica, econômica e política resultando na seletividade da clientela atingida, já que envolve questões de incorporação tecnológica, concentração de saber, campo de capitalização e alto custo. Neste sentido, no Brasil, a prática hospitalar surge mais intensamente no interior de um modelo de assistência construído num passado recente, cujas características denotam superposição de ações e irracionalidade na distribuição dos 
serviços, exclusão da população mais pobre, centralização tecnocrática de organização dos serviços, baixa resolutividade e insatisfação dos usuários(COHN, 1991).

A assistência hospitalar, neste contexło, assumiu um caráter de centralidade e alta relevância no sistema de saúde brasileiro. Dadas as suas características, tal modelo vem determinando os processos de trabalho sob o prisma da medicalização, da reprodução do saber, da concentração da clientela e de sua seletividade, das relações dos serviços com os pacientes e das formas de financiamento. Tais questões permearam, muitas vezes, 0 conteúdo das reflexões críticas que nortearam os projetos de mudança das políticas de saúde no país, quando se imprimia à prática hospitalar as principais contradições daquilo que se pretendia reformar(GONÇALVES, 1979).

Ao lado disto, depara-se com o surgimento de novas exigências por cuidados de saúde mais sofisticados, dentre eles a assistência médico-hospitalar, no conjunto das práticas de saúde. Estas exigências passam por:

- uma sociedade extremamente medicalizada nas últimas décadas, cuja representação de saúde envolve uma crescente presença de equipamentos, medicamentos, exames laboratoriais e subsidiários - atribuindo a estes, muitas vezes, a questão da eficiência e qualidade dos serviços - que ao mesmo tempo é incentivado e influenciado pela disputa de mercado, pela lógica da capitalização e da lucratividade das empresas de bens e serviços de saúde;

- mudanças no perfil demográfico e epidemiológico - transição demográfica com envelhecimento da população e predominio relativo de doenças crônicas - ocomidas no país nas últimas décadas sugerem o crescente consumo de cuidados médicos mais tecnificados e complexos (JACOBI, 1992).

No entanto, confronta-se ainda, com um modelo de organização de serviços de saúde no país, marcado por desigualdades, sendo as ações de baixo custo voltadas para os socialmente excluídos e assistência médica individual e provida de recursos tecnológicos para a população de maior nivel de renda, o que vem desafiando a busca de equidade no direito à saúde (LOBO, 1988). 


\section{ASSISTÊNCIA HOSPITALAR: UM DESAFIO À GESTÃO PÚBLICA MUNICIPAL}

A municipalização da assistência à saúde como parte da estratégia da descentralização político-administrativa definida a partir da Constituição de 1988, coloca para o poder local - os municípios - a responsabilidade pela execução de um programa técnico e político que contemple as diversas necessidades que se impõe diante da organização de um modelo de atenção à saúde(MARQUES, 1991).

E ainda, o projeto de municipalização para o setor saúde, como parte do processo de descentralização, em face da implantação de modelos assistenciais e reestruturação das práticas de saúde, deve incorporar os conceitos de democratização, universalidade, eqüidade e integralidade da atenção.

Dentro desta perspectiva, assumir a descentralização do setor saúde, significa abordar a questão da complexidade no interior de um modelo de cuidados à saúde. Em que pesem todas as dificuldades, dentro de espaços políticos, jurídicos e institucionais do atual processo de descentralização, no nível local, vêm sendo gestadas formas de organização de serviços que traduzem as várias visões e práticas deste processo, que podem ou não resultar em mudanças no atual modelo médico assistencial.

\section{LIMITES E DIFICULDADES PARA A MUNICIPALIZAÇÃO DAS AÇÕES COMPLEXAS DE SAÚDE}

A ausência de uma política mais clara para o setor hospitalar tem configurado uma situação de falência do sistema de saúde, traduzida pelo sucateamento e má administração dos hospitais públicos e agravada pelo descredenciamento acelerado devido ao desinteresse do setor privado em manter-se credenciado ao setor público. $O$ "caos" gerado pela falta de leitos para internação da população vem mobilizando inclusive a grande imprensa no sentido de denunciar o quadro de calamidade instalado a partir da implantação do Sistema Único de Saúde. 
Diante desta situação, em vários municípios a população, os profissionais de saúde e os dirigentes já se aperceberam da responsabilidade em cumprir os requisitos mínimos de universalidade, integralidade e resolutividade da atenção à saúde.

No entanto, algumas dificuldades inerentes ao próprio processo de transição em que se situa a municipalização e outras de ordem política e estrutural têm sido debatidas e enfrentadas ao tratar-se da oferta de serviços complexos de saúde, especialmente de âmbito hospitalar. Cabe assim destacar que:

- a política de assistência médico-hospitalar tem conservada a mesma lógica centralizadora, de vinte anos atrás, do ponto de vista da manutenção no âmbito federal das definições e diretrizes que estabelecem a relação entre as instâncias financiadoras e a prestação de serviços;

- a herança de um modelo construído no passado, tem gerado uma série de dificuldades para a condução da atual política de saúde. Neste aspecto, efetivar a municipalização significa enfrentar distorções provenientes da multiplicidade de instituições prestadoras de atenção à saúde, com interesses próprios e específicos;

- o grau de centralização administrativa e fiscal no âmbito federal durante o período vigente da Constituição Federal de 1967 promoveu ao longo de todos os últimos vinte anos um processo de atrofia e esvaziamento das estruturas técnicas, administrativas e financeiras dos municipios, indispensáveis no momento, para a reorganização da assistência à saúde no plano local, de acordo com os preceitos do Sistema Único de Saúde;

- a falta de tradição do município em administrar serviços de saúde de maior complexidade, haja vista que sua competência sempre esteve restrita aos serviços básicos e preventivos. Ainda há pouco, difundiam-se projetos, inclusive para fazer parte da atual Constituição, com ênfase nos cuidados primários à saúde como responsabilidade do poder local, ficando os serviços de maior complexidade tecnológica para outras esferas do govemo. É recente, portanto, a formulação que atribui ao município a responsabilidade frente a todas as ações e serviços de saúde no âmbito municipal(MÉDICl, 1992);

- diante de uma perspectiva histórica, em que sendo o hospital o local destinado à concentração e incorporação tecnológica, e uma vez concebida a descentralização como parte de um projeto de democratização da sociedade que incorpora os conceitos de acesso e universalidade, resta saber, se a atual politica de financiamento do Sistema Único de Saúde dará conta daquela modalidade assistencial em vista de seus custos cada vez mais crescentes. MENDES(1993) analis a que tal fato pode, inclusive, provocar uma "crise" pela 
tensão gerada entre custos crescentes e restrição ao acesso, na impossibilidade de conciliar as forças expansivas dos sistemas de saúde e mecanismos de controle;

- o reduzido grau de compromisso dos trabalhadores da saúde_com os objetivos organizacionais de atender às necessidades de saúde da população, a escassez de profissionais especializados em algumas regiões, associada à inexistência de políticas de capacitação, principalmente em municípios afastados dos grandes centros urbanos, a inadequação de critérios para seleção, a ausência de regulamentação da situação de servidores "estadualizados"e "municipalizados", além das dificuldades políticas de implantação de plano de carreira, cargo e salários, săo alguns pontos críticos a serem enfrentados;

- ao analisar a Constituição de 1988 e as leis correlatas, as normatizaçðes e os projetos de lei emanados do poder executivo, detectam-se fragilidades por vezes ambigüidades, ou mesmo ausência de dispositivos regulamentadores de questões vitais para o desenvolvimento do SUS. Tais problemas podem ser encontrados ao tratar-se da participação do setor privado no sistema de saúde, repartição de encargos entre as diferentes esferas de governo, principalmente no tocante aos serviços que envolvem a especialização $e$ concentração tecnológica, além dos critérios de transferência direta e automática de recursos a Estados e Municipios.

- e por fim, a questão mais complexa e crítica, do ponto de vista da assistência médico hospitalar, refere-se ao relacionamento entre os setores público e privado, haja vista que os estabelecimentos privados detêm grande parte dos leitos hospitalares existentes no país, fundamentais em diversas localidades para a atenção médica prestada pelo próprio setor público(OLIVEIRA \& TEIXEIRA, 1986). Assim, na medida em que ocorrer uma mudança 1 o processo centralizador que ora executa e define a politica de relação entre as instáncias firnancladoras e as de prestação de serviços médicos, caberá às organizações locais e intermediárias o desafio de repensar novos critérios técnicos e políticos que nortearão a parceria público/privado, e com isto atender os requisitos mínimos estabelecidos para uma politica de saúde que pretende ser integral, universal, controlada e fiscalizada pelos usuários.

Com isto, através do enfoque de algumas experiências, a partir da nova institucionalidade do poder local no campo da saúde, segundo os preceitos legais, buscou-se exemplificar maneiras distintas de tratar os aspectos que envolveram a oferta dos serviços hospitalares.

\section{OS MUNICÍPIOS DE SANTO ANDRÉ E DIADEMA E A ATENÇÃO HOSPITALAR}

Não se pretendeu aqui realizar uma análise aprofundada e comparativa dos processos decorrentes da incorporação da assistência hospitalar nos planos de organização de um 
sistema de saúde sob a gestão municipal. Até porque, para tanto seria necessário realizar um estudo anterior de tipologia de municípios para estabelecer os critérios de análise.

Desse modo, escolheu-se os municípios de Santo André e Diadema, situados na Região Metropolitana da Grande São Paulo, por apresentarem características comuns, tais como: ambos de porte médio; localizados muito próximos da metrópole; grande densidade industrial; e uma multiplicidade de questões sociais a serem enfrentadas devido ao seu crescimento desordenado. Por outro lado, apresentam questões específicas de ordem sócioeconômica e cultural que exemplificam dois processos distintos de municipalização do ponto de vista da organização dos serviços de saúde.

Apostou-se no enriquecimento da análise do processo de incorporação da assistência hospitalar na rede local de serviços, uma vez que identificou-se nos municipios escolhidos, um envolvimento das administrações municipais e da sociedade local, na busca de soluções que apontavam para a responsabilidade do poder público perante a execução de bens de consumo coletivo como no caso específico da oferta de serviços de saúde, e dentre eles, a assistência hospitalar.

E assim, procurou-se recompor, através de uma descrição sumária, o cenário onde se desenvolveram as experiências a partir dos documentos técnicos, dos relatórios de Encontros e Conferências Municipais de Saúde, dos fatos abordados pela imprensa local, de processos administrativos do executivo e do legislativo e de entrevistas com atores de destaque envolvidos.

Algumas particularidades também foram identificadas dentre os municipios de Santo André e Diadema, apesar destes se situarem na mesma região dada como homogênea (SANTO ANDRÉ, 1990):

- Santo André é um município bem mais antigo, com grande extensåo territorial, cujas primeiras instalações industriais começaram a ocorrer no início do século e com isto demarcam-se diferenças no seu processo de urbanização e características sócio-económicas; 
Diadema é um município jovem, que surgiu na década de 60 , marcado pela industrialização rápida e acentuada, porém com características distintas, pois nesta cidade instalaram-se pequenas e médias empresas nos setores metalúrgico, químico, mecánico e elétrico em complementaridade tecnológica à grande empresa multinacional. Este processo foi acompanhado por um crescimento explosivo da população, com grande fluxo de migrantes. Para se ter uma idéia, em 1950 a população girava em torno de 3.000 habitantes, e em 1970 passou para aproximadamente 80.000 habitantes.

Através de alguns indicadores pode-se reafirmar no entanto, a existência de uma diversidade de questões a serem enfrentadas por ambos os municípios, cujos dados podem expressar as contradições encontradas numa região economicamente rica, mas com sérios problemas de ordem social e de infra-estrutura urbana. A exemplo disto, pode-se citar 0 número considerável de núcleos de favelas desprovidos de infra-estrutura urbana necessária.

Do ponto de vista da oferta de serviços de saúde, Santo André, apresenta uma grande complexidade e divisão de interesses neste setor.

Conta com uma rede considerável de serviços privados organizada na década de 60 . Tal fato ocorreu muito em função de Santo André ser um município cujo processo de formação é antigo, próximo da metrópole, e possuir um padrão de desenvolvimento mais consolidado, uma população de maior poder aquisitivo e com grande inserção no mercado formal de trabalho. Estes serviços em sua grande maioria passaram a ser contratados pela Previdência Social para atendimento aos previdenciários da região. Já na década de 80 este padrão começou a sofrer alterações.

Apesar do setor privado de saúde ainda representar uma parcela considerável dos serviços de saúde no município, a manutenção de sua representação vem se dando às custas do crescimento de empresas de convênio médico de pré-pagamento. Por outro lado, a assistência à saúde do município de Santo André, oferecida pelo setor público através dos seus estabelecimentos próprios, na última década, ficavam reduzidos a 3 Unidades Básicas de Saúde com vínculo Estadual, 1 Posto de Atendimento Médico do INAMPS, 1 Hospital Municipal com 110 leitos, 2 Pronto Atendimentos Municipais para atendimento de adultos e 
1 Ambulatório de Especialidades Municipal que funcionava em colaboração com a Faculdade de Medicina do ABC. Além destes, participava a Fundação de Assistência à Infância de Santo André - FAISA, criada com finalidade beneficente para atendimento médico-hospitalar ao universo das crianças do município.

Em Diadema, pelas suas próprias características de formação histórica e perfil sócioeconômico, os serviços de saúde eram bastante simplificados do ponto de vista de sua complexidade. A iniciativa privada na saúde instalou-se em meados da década de 70 , basicamente através da prestação de serviços hospitalares oferecidos, na sua maioria, por meio de convênios com o INAMPS.

A rede pública era constituída por 1 Pronto Socorro Municipal, pequeno para abranger a demanda e sem muitos recursos para oferecer a assistência requerida por um serviço de urgência.

Existiam apenas nove unidades municipais, os chamados Postos de Puericultura, com infra-estrutura bastante reduzida. Os senviços organizados pelo Governo Estadual restringiam-se apenas a 1 Centro de Saúde destinado fundamentalmente as ações de caráter coletivo.

Foi possivel verificar em 1989 na vigência do SUS que os municípios de Santo André e Diadema apresentavam uma rede ambulatorial de saúde sucateada, com falta de integração entre os serviços existentes, obras inacabadas, fragilidade na estrutura administrativa, orçamento restrito, insuficiência de serviços públicos, salários defasados, uma dependência de serviços mis complexos, ora situados na capital e uma rede privada hegemônica iniciando um processo de funcionamento independente do Estado e voltada aos seus próprios interesses.

Apreende-se, contudo, uma preocupação das recém-empossadas administrações, em assumir o comando do sistema de saúde no âmbito municipal, além de um nítido propósito 
de fortalecer e expandir o setor público de saúde em todos os seus níveis, e que apesar destes objetivos comuns, os processos e dificuldades foram distintos do ponto de vista da organização de um sistema municipal de saúde.

No entanto, o que chamou a atenção e interessou sobremaneira este trabalho foi o processo de incorporação da assistência hospitalar nos sistemas de saúde de Santo André e Diadema a partir de 1989, já que esta questão ocupou, em ambos os municípios, um grande espaço na agenda de formulação da política local frente ao processo recente de descentralização e municipalização de saúde.

Logo no início daquelas gestões, já se percebia como reivindicação da população local a necessidade de introduzir nos seus planos a ampliação de serviços de urgência e leitos para internação.

Ao examinar os planos de saúde daquela época, verificou-se que apesar de apontarem para a necessidade de organizar alguns serviços de pronto atendimento, eles não enfatizavam uma ampliação de leitos hospitalares. A questão da assistência hospitalar era entendida pelos representantes do poder local como complexa e onerosa demais para os cofres municipais e de responsabilidade, até então, dos governos estadual e federal.

No entanto, a grave crise do setor hospitalar na região, que iniciou em 1987 com as ameaças de descredenciamento dos hospitais privados com o INAMPS, agudiza-se em 89. O descredenciamento em larga escala dos hospitais privados com o INAMPS mobiliza a opinião pública da região, precipitando uma articulação dos Secretários Municipais e Prefeitos para uma solução frente a questão. Surge como perspectiva, o término das obras do Hospital Regional de Clínicas com capacidade para 320 leitos, cuja obra havia sido iniciada em 1979 pela Prefeitura Municipal de Santo André, e ainda não concluída.

A necessidade de conclusão do Hospital Regional de Clínicas ocupa espaço na agenda da Frente Suprapartidária de Prefeitos da Região do Grande ABC. Poucos meses 
depois, a partir de mobilizações e articulações políticas, fez com que o Secretário de Estado da Saúde da época admitisse a importância de concluir as obras, tendo sido retomadas logo a seguir.

Tal fato, teve um significado importante para os municipios na medida em que desencadeou um processo de discussão local acerca da sua responsabilidade pela assistência à saúde, inclusive pela assistência hospitalar. Não obstante, a discussão e elaboração de propostas para o setor hospitalar começou a partir de então, a se individualizar no âmbito dos municípios, verificando-se encaminhamentos distintos para a questão.

A evolução das propostas para a assistência hospitalar no cotidiano das cidades caracterizaram-se, no entanto, por uma incorporação das primeiras medidas de descentralização, em 1989. Tal situação coincide com um processo importante da vida política dos municípios, marcado pela participação de vários segmentos sociais, direcionando às questões de gestão da cidade, face a elaboração das Leis Orgânicas Municipais. Nesta ocasião, intensificaram-se os debates em torno de um projeto para a saúde, particularmente em Santo André e Diadema, onde já existia uma certa mobilização social e uma discussão acumulada e direcionada para a regulamentação local dos princípios básicos do SUS.

No município de Santo André, complexo e fragmentado entre grupos de interesses, inclusive no campo da prestação de serviços de saúde, a administração municipal énfrentou a questão da assistência hospitalar com a presença de uma série de incertezas, fragilidades e conflitos. Procurou através de um processo recém inaugurado de descentralização na saúde estabelecer uma forte relação entre custo e qualidade dos serviços. Além disto, os programas de governo apontavam para os efeitos redistributivos e organizativos do sistema de prestação de serviços como um todo, inserindo os projetos de saúde na gestão das prioridades dos diversos programas sociais.

A primeira questão que se colocava em Santo André, referia-se ao financiamento das ações locais de saúde. Era possível já constatar uma retração dos investimentos para a 
saúde no município oriundos das outras esferas de governo. A proposta da administração municipal era a de ampliar substancialmente os seus recursos para o setor saúde. No entanto, sabia-se de antemão que os recursos adicionais seriam consumidos para melhorar a qualidade dos serviços hospitalares próprios do município. Em 1991, cerca de 12,5\% do orçamento municipal eram alocados para a saúde e destes, $52 \%$ eram destinados à manutenção do Hospital Municipal. Os recursos adicionais para ampliação da rede hospitalar do município foram tratados a partir de negociações do poder executivo junto ao Ministério da Saúde.

Um segundo enfrentamento que mobilizou a opinião pública da cidade, o legislativo e a própria administração municipal, foi o projeto de autarquização do Hospital Municipal com o objetivo de permitir um gerenciamento mais ágil e autônomo.

Tal proposta encaminhada pelo executivo à Câmara de Vereadores como Projeto de Lei, não foi aprovado apesar dos inúmeros debates, negociações e modificações no projeto inicial sob a alegação de "inchaço" na máquina administrativa da Prefeitura e risco de perda do controle administrativo e financeiro ao desconcentrar determinadas atividades alocadas na administração central da Prefeitura. No final, o executivo acabou retirando a última versão do Projeto de Lei motivado pelo esgotamento do processo de negociações.

Mesmo assim, verificou-se pelos inúmeros relatórios, melhorias no Hospital Municipal, tais como: algumas adequações na estrutura física; aumento e diversificação do quadro de pessoal; qualificação da equipe gerencial; definição ainda que informal das atribuições da Faculdade de Medicina do ABC no hospital; criação do Conselho Gestor; expansão e melhoria da resolutividade dos serviços prestados.

Apesar daquelas iniciativas, buscando otimizar e melhorar o Hospital Municipal, ficava evidente ainda, nos documentos estudados, a pressão social alertando para a necessidade de ampliação do número de leitos hospitalares acessíveis a população dependente do SUS.

Neste sentido, a Secretaria de Saúde de Santo André, elaborou uma proposta a ser 
discutida com o setor privado da saúde sobre a disposição de leitos para a clientela do SUS nos hospitais privados, com a contrapartida da isenção de ISS, alternativa esta, polêmica junto ao setor de planejamento e finanças da prefeitura. Mesmo assim, tentou-se uma aproximação com os diretores daqueles hospitais. $O$ resultado desta tentativa ficou restrito a possibilidade de diálogo junto a um único hospital da cidade que respondia por uma parcela considerável de leitos antes credenciados pelo INAMPS em processo de descredenciamento.

A direção do æeferido hospital apresentou uma série de obstáculos, e por fim, não manifestou interesse, pois seus projetos já estavam voltados para a adequação física da estrutura hospitalar para a atração de convênios médicos em franca expansão na região. Além do que, 0 argumento era de que um acordo com o setor público implicaria em ter que reativar a porta do hospital, caracterizando-o como um senviço que atenderia a clientela do SUS, o que prejudicaria a imagem da instituição frente aos novos projetos para o hospital. Ainda preocupava o fato das ingerências e pressões políticas de um possível acordo com o poder público.

O envolvimento de setores da população, frente a questão hospitalar, propiciou o surgimento de novas alternativas. Foi quando um grupo de moradores do $2^{\circ}$ Subdistrito da cidade de Santo André junto a uma organização religiosa apresentou a proposta de desapropriação de um Seminário da Sociedade de Missionários Franciscanos à administração municipal, cujo prédio estava alugado a um grupo privado de empresários da saúde. A proposta de desapropriação foi encampada pela Administração Municipal no final de 1991 para o funcionamento a curto prazo de 100 leitos hospitalares. Várias negociações junto ao Ministério da Saúde e Secretaria Estadual da Saúde foram realizadas durante o ano de 1992. As negociações, no entanto, não obtiveram uma solução concreta para a viabilização do projeto. Dentre os motivos que o inviabilizaram cabe destacar a não concordância por questões jurídicas apresentadas pela Secretaria de Estado da Saúde em desapropriar um prédio que já era utilizado para o funcionamento de um hospital, mesmo com finalidade lucrativa, apesar deste não possuir na época, condições físicas adequadas e nem alvará de funcionamento expedido pela Vigilância Sanitária Regional. 
E assim, Santo André, no processo de elaboração de uma proposta mínima para a assistência hospitalar do ponto de vista institucional procurou trabalhar, de um lado, com a realidade interna de uma administração recém empossada com compromissos e prioridades estabelecidas de gestão urbana vulnerável a um conjunto de pressões emanadas da sociedade local. De outro, com a construção de novos espaços fora do domínio da administração municipal (partidos políticos, Câmara de Vereadores, entidades de classe, associações de empresários, etc.) que naquele momento já se apropriavam desta situação específica.

No entanto, a síntese das propostas de garantia do acesso da população à assistência hospitalar no município de Santo André só pode ser melhor delineada no final da gestão. Contudo, destaca-se como resultado um processo dinâmico que envolveu embates políticos com o executivo no nivel central, com o legislativo, com as lideranças e suas bases, com as organizações populares e com as demais instâncias govemamentais. Além do que, percebese através dos documentos analisados que os debates foram permeados por discussões que envolviam desde a concepção do papel do Estado e as novas competências do poder local no campo da saúde, até aquelas de cunho estrutural imprescindiveis para a gestão local dos serviços de saúde.

O desenvolvimento de um projeto de assistência hospitalar para o município de Diadema, assumiu uma trajetória distinta.

Neste caso, o município não contava com leitos públicos próprios: havia praticamente uma continuidade do trabalho desenvolvido pela gestão anterior, cujo recém empossado Prefeito da cidade, já havia participado daquela gestão como Secretário da Saúde, com um projeto de atuação mais claro para o setor; a existência de uma complexidade menor de instituições prestadoras de serviços de saúde; uma maior homogeneidade da estrutura social; uma menor inserção do setor privado da saúde com menor interesse de expansão; poucos grupos políticopartidários; proximidade com cidades importantes em termos de oferta de bens e serviços (Santo André, São Bernardo do Campo e São Paulo); além de um trabalho anterior mais consolidado e integrado entre o executivo e os movimentos populares da cidade. 
O problema começou a ser enfrentado pela Prefeitura Municipal de Diadema, com uma forte articulação com as organizações populares, em meados de 1989, trabalhando a questão no sentido de buscar recursos nas outras instâncias governamentais para instalação de um Hospital Público Municipal na cidade.

Foi um período de intensa mobilização da população e representantes da administração do município para que Diadema fosse contemplada com a possibilidade de recursos do Banco Mundial - Programa Metropolitano de Saúde (P.M.S.) para a construção de um hospital na cidade.

Em setembro de 1989, o então Secretário Estadual da Saúde, em assembléia pública, assumiu o compromisso imediato de implantar um hospital de 220 leitos em Diadema. A Secretaria Estadual da Saúde desenvolveria o projeto, contrataria uma empresa para a execução das obras e se responsabilizaria pelo gerenciamento da mesma, segundo as normas do P.M.S.. A Prefeitura desapropriou um terreno e logo a seguir foram iniciadas as obras do Hospital Geral. Em 1992, o Governo do Estado paralisou a construção, alegando a falta de repasse de recursos financeiros por parte do Ministério da Saúde.

Ainda em 1989, paralelamente à luta pela construção do Hospital Geral, diante da grave situação enfrentada pelo descredenciamento dos leitos, e considerando 4 anos, o tempo necessário para a conclusão daquele hospital, surge a possibilidade do repasse ao poder público de um hospital privado da rede SAMCIL situado em Diadema, pela impossibilidade de seus proprietários saldarem as dívidas de financiamento com a Caixa Econômica Federal.

E assim ocorreu, a Secretaria de Estado da Saúde de São Paulo intermediou e autorizou o gerenciamento administrativo do referido hospital a Prefeitura Municipal de Diadema. A Administração Municipal negociou com o repasse de recursos para a adequação da estrutura física e aquisição de equipamentos. Conseguiu-se que o repasse de recursos fosse realizado inclusive com os reajustes financeiros, o que minimizou os gastos com a 
reforma e aquisição de equipamentos. Além do que, o gerenciamento das obras, realizado pela própria prefeitura propiciou uma acentuada diminuição dos custos com a construção. Mesmo assim, houve a necessidade de investimentos do Tesouro Municipal para o término do projeto. O Hospital Público Municipal de Diadema, iniciou o atendimento à população em janeiro de 1992 , com $50 \%$ da sua capacidade operacional.

Outra iniciativa do município para ampliar o número de leitos públicos hospitalares foi a criação do Hospital Infantil Municipal com 40 leitos, a partir de um prédio que seria destinado a uma creche, construída pelo Governo do Estado, sendo adaptado e equipado para o funcionamento do referido hospital com recursos próprios municipais e inaugurado em fins de 1992.

É preciso considerar que para a viabilização de tais iniciativas, apesar das dificuldades encontradas, principalmente de financiamento, estas foram de certa forma contornadas pela alocação crescente de recursos financeiros provenientes do orçamento próprio do município, pela manutenção de um patamar elevado dos níveis salariais, compatíveis com o mercado da região e com o crescimento considerável do corpo de funcionários na área da saúde.

Contudo, o que chamou a atenção no caso de Diadema, foi o curto espaço de tempo em que ocorreram tais realizações. Ao entrevistar alguns profissionais que participaram da coordenação técnica de desenvolvimento dos projetos na área hospitalar do município, estes ponderaram que apesar da organização centralizada da máquina administrativa da prefeitura, percebia-se um envolvimento global da administração e entusiasmo para driblar as dificuldades encontradas, com improvisações no sentido de desburocratizar a agilizar os processos administrativos que tinham como objetivo aquele fim. Facilitou, porém, esta postura o fato de ser uma prefeitura de menor porte, mais recente e menos impregnada pela rigidez da burocracia.

Por fim, no encerramento da gestão, avaliou-se que o município de Diadema conseguiu empreender uma política de assistência hospitalar com o aumento da oferta de leitos públicos 
na cidade, ainda que o Departamento de Saúde e os órgãos gestores da saúde considerassem as conquistas ainda insatisfatórias para as necessidades da maioria da população de Diadema.

\section{CONCLUSÃO}

A reconstrução do processo de descentralização na saúde, a partir de realidades distintas, demonstrou diferenças significativas quanto ao enfrentamento das questões que envolveram a assistência médico-hospitalar em Santo André e Diadema.

As distintas trajetórias do desenvolvimento das propostas para a assistência hospitalar, em ambos os municipios, inovaram principalmente pelo fato da ousadia com que foi tratada a questão, diante das inúmeras dificuldades já mencionadas. $E$ ainda, permitem uma reflexão acerca das possibilidades e indefinições de uma política recente de descentralização da saúde, que procura dentre outras, propor um novo reordenamento para a assistência médica.

As experiências no nivel local, no entanto, devem ser analisadas à luz das particularidades de cada instância de poder, da sua formação histórica, vida local, interações sociais, estruturas e modelos político-administrativos, representação política, interesses privados e determinação econômica da política local.

Ficou evidente no decorrer da análise do objeto de estudo naqueles municípios escolhidos a preocupação com aspectos relacionados a questão da política de financiamento, à busca de mecanismos gerenciais diferenciados, inclusive com o envolvimento da população, e a tentativa de relacionamento com instituições privadas, filantrópicas e outras instâncias de poder.

Por outro lado, ao contexłualizar a participação das instâncias do Governo Estadual e Federal no processo de discussão e elaboração de um projeto de assistência hospitalar para a região e municípios, verificou-se que praticamente durante todo o período em análise, tais instâncias limitaram-se apenas a acompanhar as demandas trazidas pelas prefeituras e 
analisar as propostas do ponto de vista da viabilidade de recursos financeiros para a implantação das mesmas, ao invés de atuarem como co-partícipes de um projeto de elaboração de uma política de atenção hospitalar de âmbito regional.

Apesar dos limites e das dificuldades - quanto ao financiamento, aos recursos humanos, a organização de uma rede de assistência à saúde, ao relacionamento do sètor público com o privado, e envolvimento com as demais instâncias de poder - para o desenvolvimento e implantação dos projetos de assistência hospitalar, pode-se aprender que no nivel local, a partir das distintas experiências relatadas, tais questões foram de certa forma enfrentadas, sob as particularidades de cada município. No entanto, tais dificuldades e limites, dificilmente serão resolvidos no âmbito interno das cidades, necessitando de uma melhor explicitação e, em alguns casos, do próprio cumprimento da legislação já existente que trata destas questões.

Embora com pesos e características distintas na organização administrativa, infraestrutura própria de serviços de saúde, na rede privada de saúde e condição política diferenciada, ficou claro através do enfoque de assistência hospitalar que ambos os municípios investiram no ideário de acesso universal, na participação social e na relação do poder local com outras esferas de poder (regional e central), apesar das dificuldades encontradas no decorrer da implantação naquelas cidades de um projeto de cuidados à saúde que pretendia ser igualitário, integral e resolutivo.

Com isto, ficou claro que dentre os princípios democráticos estabelecidos pela sociedade e conferido maior concretude na carta constitucional, pode-se reafirmar que: o acesso universal visa a equidade, e a equidade implica suplantar o acesso à atenção de primeira linha, incorporando-se nos projetos de reforma do modelo de atenção à saúde, a assistência que envolve maior tecnologia. Tal fato remete a questão para uma definição do financiamento do setor, de uma política de recursos humanos, de um efetivo controle público, da relação com o setor privado da saúde e da interação entre as diferentes esferas de governo. 


\section{REFERÊNCIAS BIBLIOGRÁFICAS}

BRASIL. Constituição, 1988. Constituição da República Federativa do Brasil, Art. 196-202. São Paulo, Imprensa Oficial do Estado, 1988.

COHN, A. et al. A saúde como direito e como serviço. São Paulo, Cortez/CEDEC, 1991.

GONÇALVES, R. B. M. Medicina e história: raízes sociais do trabalho médico. São Paulo, 1979. [Dissertação de Mestrado - Faculdade de Medicina da USP]

JACOBI, P. Descentralização municipal e participação dos cidadãos: apontamentos para o debate. Cad. da Nona, 1:113-20, 1992.

LOBO, T. Descentralização - uma alternativa de mudança. Rev. Ad. Pública, 22:14-24, 1988.

MARQUES, M.B. Ciência, tecnologia, saúde e desenvolvimento sustentado. Rio de Janeiro, FIOCRUZ, 1991. Série Política de Saúde.

MÉDICI, A.C. Incentivos governamentais ao setor privado de saúde no Brasil. Rev. Adm. Públ., 26:79-115, 1992.

MENDES, E.V. Cinco razões para o fim do INAMPS. Saúde em Debate, (39):26-34, 1993.

OLIVEIRA, J.A.A. \& TEIXEIRA, S.M.F. (IM) Previdência social: 60 anos de história da previdência no Brasil. Petrópolis, Vozes, 1986.

SANTO ANDRÉ. Secretaria de Educação, Cultura e Esportes. Congresso de História da Região do Grande $A B C, 10$, Santo André, 1990.

Summary: The offering of hospital services in face of the recent politico-administrative decentralisation and municipalization of health process on Brazil comes up as a challenge to local management. The production of immediate responses within a dynamic accelerated non-linear context of political incorporation of social rights given the complexity involving medico-hospital assistance leads to a necessary reflection on the potentialities and limits of the directives of the current health policy. Despite the complexity of the issue the different trajectories of the hospital services management project development in the municipalities of Santo André and Diadema innovate the responsibilities of local power to meet the conceptual and political aspects of decentralisation.

Key words: medico-hospital assistence, hospital services management, municipalization, descentralization 